\title{
Income and patient-reported outcomes (PROs) after primary total knee arthroplasty
}

Jasvinder A Singh ${ }^{1,2,3^{*}}$ and David G Lewallen ${ }^{3}$

\begin{abstract}
Background: To assess whether income is associated with patient-reported outcomes (PROs) after primary total knee arthroplasty (TKA).

Methods: We used prospectively collected data from the Mayo Clinic Total Joint Registry to assess the association of income with index knee functional improvement, moderate to severe pain and moderate to severe activity limitation at 2-year and 5-year follow-up after primary TKA using multivariable-adjusted logistic regression analyses.

Results: There were 7, 139 primary TKAs at 2 years and 4, 234 at 5 years. In multivariable-adjusted analyses, at 2-year follow-up, compared to income > US\$45, 000, lower incomes of $\leq$ US\$35, 000 and $>$ US\$35, 000 to 45, 000 were associated (1) significantly with moderate to severe pain with an odds ratio (OR) 0.61 ( $95 \% \mathrm{Cl} 0.40$ to 0.94 ) $(P=0.02)$ and $0.68(95 \% \mathrm{Cl} 0.49$ to 0.94$)(P=0.02)$; and (2) trended towards significance for moderate to severe activity limitation with OR $0.78(95 \% \mathrm{Cl} 0.60$ to 1.02$)(P=0.07)$ and no significant association with $\mathrm{OR} 0.96(95 \% \mathrm{Cl}$ 0.78 to 1.20$)(P=0.75)$, respectively. At 5 years, odds were not statistically significantly different by income, although numerically they favored lower income. In multivariable-adjusted analyses, overall improvement in knee function was rated as 'better' slightly more often at 2 years by patients with income in the $\leq$ US\$35, 000 range compared to patients with income > US\$45, 000, with an OR $1.9(95 \% \mathrm{Cl} 1.0$ to 3.6) $(P=0.06)$.

Conclusions: We found that patients with lower income had better pain outcomes compared to patients with higher income. There was more improvement in knee function, and a trend towards less overall activity limitation after primary TKA in lower income patients compared to those with higher incomes. Insights into mediators of these relationships need to be investigated to understand how income influences outcomes after TKA.
\end{abstract}

Keywords: arthroplasty, income, joint replacement, patient-reported outcomes, risk factor, total knee replacement

\section{Background}

Total knee arthroplasty (TKA), a common surgical procedure with a rapidly increasing annual volume in the USA [1], is associated with significant improvement in pain, function and quality of life [2]. However, $10 \%$ to $30 \%$ of patients continue to have refractory pain and/or significant functional limitation even years after TKA or total hip arthroplasty [3-5]. Identification of significant predictors of post-arthroplasty pain and functional limitation [6-9] will allow us to design interventions targeting risk modifiable factors, with a likelihood of improving outcomes. Much emphasis in the previous studies has

\footnotetext{
* Correspondence: jasvinder.md@gmail.com

${ }^{1}$ Medicine Service and Center for Surgical Medical Acute are Research and Transitions (C-SMART), Birmingham VA Medical Center, 700 19th Street South Birmingham, AL 35233, USA

Full list of author information is available at the end of the article
}

been placed on implant and surgical aspects of arthroplasty and its demographic predictors, with very few studies focusing on socioeconomic predictors. It is well established that patients with low income are less likely to receive total joint replacement [10-14], which also partially explains the racial disparity in total joint replacement utilization $[12,13,15,16]$. Need and willingness to undergo joint arthroplasty does not differ by income level [17].

Few studies have examined the association of lower income with arthroplasty outcomes. To the best of our knowledge, there has been only one study in a TKA cohort [18]. This study found no differences in pain and function outcomes 2 years after TKA by income level, but higher gains in a lower income group [18]. Additional studies in hip arthroplasty populations have yielded

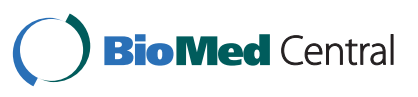


contradictory results. Lower income was either associated with higher risk of medical complications in a population-based Italian study [14] and in the Medicare population [19] or not associated with patient satisfaction or likelihood of achieving excellent hip function in a US study [20] in hip arthroplasty cohorts. Since data are based on small samples with limited follow-up and not conclusive, well designed studies with adequate power that assess this relationship in larger samples post TKA are needed. We hypothesized that lower income would predict poorer absolute scores in pain and function post TKA, but more improvement in function outcomes with TKA compared to preoperative scores. Using data from a large institutional total joint registry, we examined the association of income with moderate to severe pain, moderate to severe activity limitation and improvement in knee function at 2 and 5 years after primary TKA.

\section{Methods}

The current study used the data collected in the Mayo Total Joint Registry, one of the largest US joint registries [21]. The Mayo Total Joint Registry collects prospective data on all joint replacements performed at the Mayo Clinic including patient demographics and clinical characteristics (body mass index (BMI)); reoperations, complications and whether the implant was in place or removed; current radiographs; and pain and function assessments [22,23]. The Mayo Knee questionnaire [24] is reliable and is based on the American Knee Society scale, a validated instrument that is most commonly used in evaluation of knee arthroplasty patients [25-27]. The pain and function questions analyzed in this study from the Mayo Knee questionnaire are the same as those in the Knee Society Score [28]. Questionnaires are administered to all patients undergoing knee arthroplasty at the Mayo Clinic, and these data have been captured electronically since 1993. The questionnaires are mailed to the patients, administered during the clinic visit or by telephone by experienced, dedicated joint registry staff at 2-year and 5-year timepoints after TKA. Patients were included in this study if they had undergone a primary TKA during 1993 to 2005 and had responded to either a 2-year or 5-year follow-up questionnaire. The study was approved by the Mayo Clinic's Institutional Review Board.

\section{Predictor variable and its definition}

The predictor of interest was the patient's income at the time of index arthroplasty, as assessed based on patient zip codes and the median household income for geographical area using the census data for the respective year of survey. Income was categorized into $\leq$ US $\$ 35,000$, > US $\$ 35$, 000 to US\$45, 000 and > US $\$ 45,000$ levels, as previously $[8,9,29,30]$. Categories were created based on the fact that
US\$35, 000 was twice the poverty level income for a family of four in 1998 to 1999, the midpoint of our study [31]. Additional sensitivity analyses were performed with a different income cut-off.

\section{Outcomes of interest}

We assessed three key patient-reported outcomes at 2 years and 5 years after TKA. Two outcomes indicated 'state' post TKA (moderate to severe pain and moderate to severe activity limitation) and one indicated 'change' after TKA (knee function improvement from before to after surgery):

(1) Moderate to severe knee pain: assessed based on the responses to a question regarding pain in knee similar to the pain question in the Knee Society Scale [25] 'Do you have pain in the knee in which the joint was replaced?', with responses of no pain, mild (occasional), stairs only, walking and stairs combined into reference category and moderate (occasional), moderate (continuous) and severe pain combined into moderate to severe pain, similar to previous studies $[5,9,32]$.

(2) Moderate to severe activity limitation: this was defined as the presence of moderate or severe limitation in two or more of the three activities queried (walking, stairs, rising chair), as previously $[29,32]$.

(3) Improvement in knee function: this was assessed with the single question 'Compared to your condition before your knee surgery, how would you rate your knee function?', with responses of much better, better, same or worse. Responses of same and worse were combined into the reference category, as described previously [32].

\section{Covariates of interest}

The covariates included factors previously shown to be associated or potentially associated with pain and function outcomes after TKA [5,9,23,33-35]. These included patient characteristics (age, gender, BMI), comorbidity, American Society of Anesthesiologists (ASA) score, preoperative pain and preoperative activity limitation (in respective models), implant fixation (cemented/hybrid versus not cemented), underlying diagnosis (osteoarthritis, rheumatoid/inflammatory arthritis or other) and distance from medical center (categorized $<100,100$ to 500 and $>500$ miles/overseas). Age was categorized into $\leq 60,61$ to 70, 71 to 80 and $>80$ categories, as previously [5,36]. BMI was categorized, as previously [37], into $\leq 25,25.1$ to $29.9,30$ to $34.9,35$ to 39.9 and $\geq 40 \mathrm{~kg} / \mathrm{m}^{2}$. Comorbidity was measured by Deyo-Charlson score, the most commonly used validated comorbidity measure [38] consisting of a weighted scale of 19 comorbidities (including cardiac, pulmonary, renal, hepatic disease, diabetes, cancer, HIV and so on), expressed as a summative score $[39,40]$, with a higher score indicates more comorbidity. ASA score, a validated measure of perioperative and postoperative 
outcomes, was categorized as class I to II versus III to IV $[41,42]$.

\section{Statistical analyses}

Responder and non-responder characteristics were compared using logistic regression analyses. Multivariableadjusted logistic regression analyses were performed separately for each of the three prespecified outcomes at prespecified timepoints of 2 and 5 years (six models). For these analyses, we used a generalized estimating equations (GEE) approach to adjust for the correlation between observations on the same subject (for example, if a patient underwent right and left primary TKA). The main multivariable-adjusted analyses adjusted for several baseline variables including age category, gender, BMI category, comorbidity, ASA class, operative diagnosis, distance from the medical center and implant fixation. Since improvement in knee function had three categories (much better, better versus same/worse (reference)), we used polytomous logistic regression, which does not make any assumption of parallel slopes (as is made in ordinal logistic regression) [43,44]. Odds ratios $(\mathrm{OR})$ and the $95 \%$ confidence intervals (CI) are presented. A $P$ value $<0.05$ was considered significant. We performed additional sensitivity analyses for pain and activity limitation outcomes: (1) adding preoperative pain to the function outcome analyses and preoperative function to the pain analyses; (2) varying the income category cut-offs to two times the poverty level in 2005 (US\$39, 000); and (3) including age and BMI as continuous variables, instead of categorical variables. Since improvement in knee function incorporates preoperative status, these models were not additionally adjusted for preoperative variables, to avoid overadjustment.

\section{Results}

\section{Patient characteristics and responder bias}

Patient characteristics for TKA cohorts at 2-year and 5year follow-up are shown in Table 1. At 2-year follow-up, the mean age was 68 years, $56 \%$ were women, $9 \%$ had BMI $\geq 40 \mathrm{~kg} / \mathrm{m}^{2}$, and $42 \%$ had ASA class III or IV. Medical comorbidities, anxiety and depression were common. Detailed characteristics for 5-year follow-up are provided in Table 1.

The response rate was $65 \%(7,139 / 10,957)$ at 2 years and $57 \%(4,234 / 7,404)$ at 5 years. For primary TKA 2-year and 5-year follow-up, male gender, osteoarthritis diagnosis, older age, lower ASA class, lower Deyo-Charlson comorbidity index score and shorter distance from medical center $(<100$ miles) were associated with greater odds of response.

Unadjusted prevalence of suboptimal pain, activity limitation and index knee function improvement outcomes is shown in Table 2.

\section{Income and outcomes after primary TKA}

\section{State outcomes}

For unadjusted models, the lowest income category ( $\leq$ US $\$ 35,000)$ was associated with significantly lower odds of moderate to severe pain $(P=0.01)$ and moderate to severe activity limitation at 2 years $(P=0.04)$ and borderline significant association of the US\$35, 000 to 45,000 income category with lower odds of moderate to severe pain at 2 years, compared with the highest income category $(P=0.06$; Table 3$)$. In multivariable-adjusted models that also adjusted for the respective preoperative variable, both lower income categories ( $\leq$ US $\$ 35,000$ and $>$ US $\$ 35,000$ to US $\$ 45,000)$ were associated with significantly lower odds of moderate severe pain $(P=0.02$ each), and a borderline significant difference in odds of moderate to severe activity limitation at 2 years post primary TKA, compared to the higher income group (> US $\$ 45,000 ; P=0.07$ ) (Table 4). Similar differences were seen at 5 years, but these were not significant. Sensitivity analyses that adjusted for preoperative pain in the activity limitation model (and vice versa; see Additional file 1), varied the income categories (Additional file 2) or examined age and BMI as continuous variables (Additional file 3), did not effect the interpretation of study results for moderate to severe pain or moderate to severe activity limitation outcomes.

\section{Change outcome}

For unadjusted models, the lowest income category ( $\leq$ US $\$ 35,000$ ) was associated with higher odds of 1.5 for better index knee function at 2 years, but this did not reach significance $(P=0.13$; Table 3$)$. In multivariable-adjusted models, a lower income ( $\leq$ US $\$ 35,000$ ) was associated with higher odds of having more index knee function improvement ('better') relative to the preoperative function, as compared to the higher income category (> US $\$ 45,000)(P=0.06$; Table 5). Numerically higher but statistically non-significant odds of 'much better' functional improvement were seen at 2 and 5 years in those with a lower income ( $\leq$ US $\$ 35,000)$. Less impressive differences were seen in the > US $\$ 35,000$ to US $\$ 45,000$ income category.

\section{Discussion}

In this study, interestingly we found that lower income was associated with better pain outcome at 2 years after primary TKA. We also found that patients with lower income saw more improvement in overall knee function from pre-TKA to post-TKA evaluation, compared to higher income patients. Similar, but non-significant, associations were noted at 5 years. Several study findings merit further discussion, but need to be interpreted considering study limitations.

Our study has several limitations. A non-response bias may limit the generalizability of our findings. The response 
Table 1 Clinical and demographic characteristics of patients

\begin{tabular}{|c|c|c|}
\hline & \multicolumn{2}{|c|}{ Primary TKA, $n^{a}(\%)$ unless specified otherwise } \\
\hline & 2 years $(n=7,139)$ & 5 years, $(n=4,234)$ \\
\hline Men/women & $3,162(44.3 \%) / 3,977(55.7 \%)$ & $1903(44.9 \%) / 2,331(55.1 \%)$ \\
\hline Age, mean \pm SD & $68.4 \pm 10.0$ & $68.4 \pm 9.6$ \\
\hline \multicolumn{3}{|l|}{ Age groups, $n(\%)$ : } \\
\hline$\leq 60$ years & $1,313(18.4 \%)$ & $745(17.6 \%)$ \\
\hline$>60$ to 70 years & 2, $531(35.5 \%)$ & $1,576(37.2 \%)$ \\
\hline$>70$ to 80 years & 2, $734(38.3 \%)$ & 1, $617(38.2 \%)$ \\
\hline$>80$ years & $561(7.9 \%)$ & $296(7.0 \%)$ \\
\hline \multicolumn{3}{|l|}{ Body mass index, kg/m²: } \\
\hline$<25$ & $934(13.1 \%)$ & $566(13.4) \%$ \\
\hline 25 to 29.9 & 2, $479(34.7 \%)$ & 1, $525(36.0 \%)$ \\
\hline 30 to 34.9 & 2, $092(29.3 \%)$ & $1,250(29.5 \%)$ \\
\hline 35 to 39.9 & $976(13.7 \%)$ & $573(13.5 \%)$ \\
\hline$\geq 40$ & $605(8.5 \%)$ & $303(7.2 \%)$ \\
\hline \multicolumn{3}{|l|}{ ASA score: } \\
\hline Class | to || & 4, $115(57.6 \%)$ & 2, $467(58.3 \%)$ \\
\hline Class III to IV & $3,006(42.1 \%)$ & 1, $741(41.1 \%)$ \\
\hline Deyo-Charlson Index, mean \pm SD & $1.2 \pm 1.9$ & $1.1 \pm 1.9$ \\
\hline \multicolumn{3}{|l|}{ Key Deyo-Charlson comorbidities: } \\
\hline Myocardial infarction & $341(4.8 \%)$ & $202(4.8 \%)$ \\
\hline Peripheral vascular disease & $370(5.2 \%)$ & $190(4.5 \%)$ \\
\hline Renal disease & $397(5.6 \%)$ & $175(4.1 \%)$ \\
\hline Chronic obstructive pulmonary disease & $762(10.7 \%)$ & $408(9.6 \%)$ \\
\hline Diabetes & $669(9.4 \%)$ & $349(8.2 \%)$ \\
\hline Connective tissue disease & $520(7.3 \%)$ & $352(8.3 \%)$ \\
\hline Anxiety & $465(6.5 \%)$ & $220(5.2 \%)$ \\
\hline Depression & $741(10.4 \%)$ & $334(7.9 \%)$ \\
\hline \multicolumn{3}{|l|}{ Distance from medical center: } \\
\hline 0 to 100 miles & $3,669(51.4 \%)$ & 2, $080(49.1 \%)$ \\
\hline$>100$ to 500 miles & 2, $731(38.3 \%)$ & 1, $653(39.0 \%)$ \\
\hline$>500$ miles & $541(7.6 \%)$ & $327(7.7 \%)$ \\
\hline \multicolumn{3}{|l|}{ Diagnosis: } \\
\hline Inflammatory arthritis & $256(3.6 \%)$ & $189(4.5 \%)$ \\
\hline Osteoarthritis & $6,710(94.0 \%)$ & 3, $922(92.6 \%)$ \\
\hline Other & $172(2.4 \%)$ & $123(2.9 \%)$ \\
\hline
\end{tabular}

${ }^{a}$ Missing values for 2-year cohort: 27 were missing body mass index (BMI), 18 were missing American Society of Anesthesiologists (ASA) class, 3 were missing Charlson Index scores, 198 were missing the distance variable, 1 was missing operative diagnosis. Missing values for 5-year cohort: 17 were missing BMI, 26 were missing ASA class, 174 were missing the distance variable, 23 were missing operative diagnosis.

Table 2 Prevalence of pain and function outcomes by income category

\begin{tabular}{|c|c|c|c|c|}
\hline & \multirow[t]{2}{*}{ Moderate to severe pain } & \multirow[t]{2}{*}{ Moderate to severe functional limitation } & \multicolumn{2}{|c|}{ Overall knee status } \\
\hline & & & Better & Much better \\
\hline \multicolumn{5}{|l|}{2 years: } \\
\hline$\leq$ US\$35, 000 & $5.7 \%$ & $19.6 \%$ & $10.9 \%$ & $85.7 \%$ \\
\hline > US\$35, 000 to US\$45, 000 & $6.7 \%$ & $22.9 \%$ & $8.8 \%$ & $87.5 \%$ \\
\hline$>$ US\$45, 000 & $8.2 \%$ & $23.1 \%$ & $8.5 \%$ & $87.6 \%$ \\
\hline \multicolumn{5}{|l|}{5 years: } \\
\hline$\leq$ US\$35, 000 & $7.2 \%$ & $28.0 \%$ & $9.4 \%$ & $85.6 \%$ \\
\hline > US\$35, 000 to US\$45, 000 & $7.5 \%$ & $29.7 \%$ & $9.3 \%$ & $85.4 \%$ \\
\hline$>$ US\$45, 000 & $8.2 \%$ & $29.6 \%$ & $9.7 \%$ & $84.4 \%$ \\
\hline
\end{tabular}


Table 3 Unadjusted association of income with pain, activity limitation and improvement in knee function after primary total knee arthroplasty

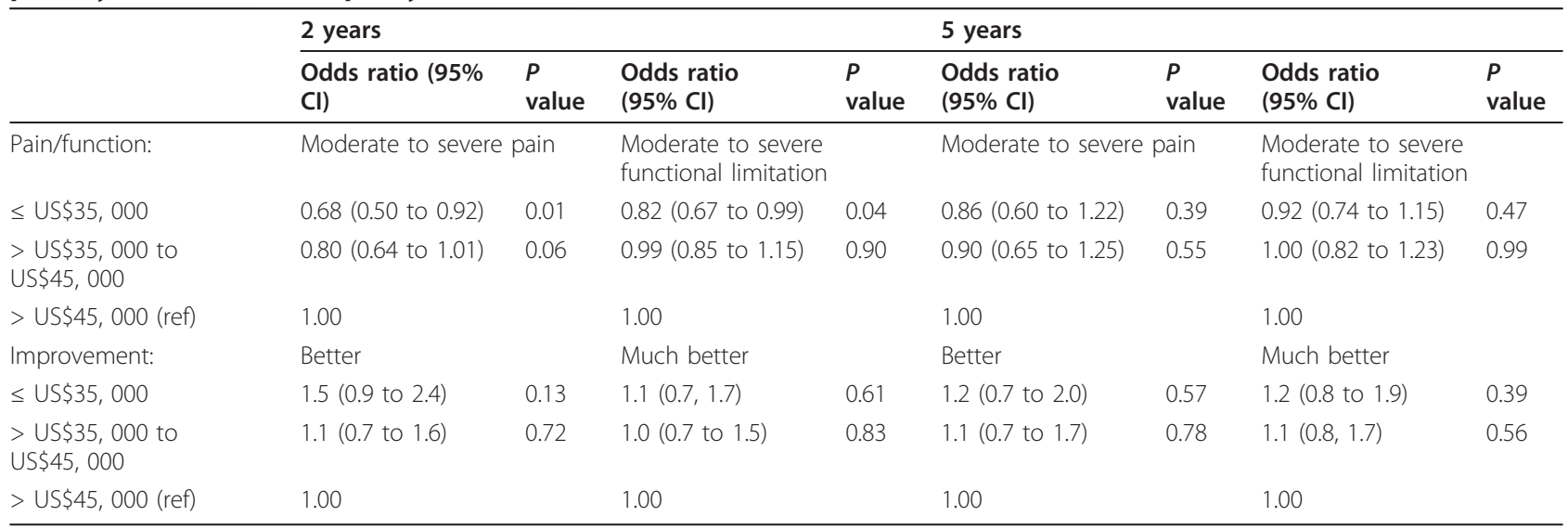

rate of $65 \%$ and $57 \%$ for pain and function surveys at 2 and 5 years is similar to the average survey response rate of $60 \%$ for large surveys such as ours [45]. However, the study cohort's clinical and demographic characteristics are similar to TKA cohorts reported previously. Income was based on zip code median income, and not actual personal income, which may have led to misclassification bias. Whether this biased our results towards or away from the null hypothesis is not entirely clear. People with the same income in different parts of the US (New York versus Midwest versus South) have slightly different purchasing power. Although this does not impact the observed associations, the variation in purchasing power by geography may impact access to health care even for those with similar socioeconomic status. Even though we specified the three outcomes a priori, with the Bonferroni adjustment, our findings may be considered borderline significant for such a conservative approach (with a corrected $P$ value of 0.017 for three comparisons). Study strengths included adjustment for important covariates, robust results in multivariable-adjusted analyses and multiple sensitivity analyses, a large sample size with lower risk of a type II error, analyses of both pain and function outcomes and examination of both 'state' and 'change' variables for outcomes.

A key interesting finding in our study was the lower risk of moderate or severe pain post TKA in patients with lower income. In a recent TKA study that included patients from four countries including the US, lower income was reported as not significantly associated with pain and function outcomes up to 2 years after TKA $(P=$ 0.07) [18]. On closer inspection, the Western Ontario and McMaster Universities Arthritis Index (WOMAC) pain scores (higher $=$ worse) for income categories $<$ US $\$ 15,000$, US $\$ 15,000$ to 30,000 , US $\$ 30,000$ to 45,000 , US $\$ 45,000$ to 60,000 and $>$ US $\$ 60,000$ were $78,83,80$, 82 and 87 respectively $(P=0.014)$; that is, significantly less pain in patients with lower income at 1 year [18]. In fact similar lower scores were also noted for lower income categories at 2 years, but the level of statistical

Table 4 Multivariable-adjusted association of income with pain and activity limitation after primary total knee arthroplasty

\begin{tabular}{|c|c|c|c|c|c|c|c|c|}
\hline & \multicolumn{4}{|l|}{2 years } & \multicolumn{4}{|l|}{5 years } \\
\hline & \multicolumn{2}{|c|}{ Moderate to severe pain } & \multicolumn{2}{|c|}{$\begin{array}{l}\text { Moderate to severe } \\
\text { functional limitation }\end{array}$} & \multicolumn{2}{|c|}{ Moderate to severe pain } & \multicolumn{2}{|c|}{$\begin{array}{l}\text { Moderate to severe } \\
\text { functional limitation }\end{array}$} \\
\hline & $\begin{array}{l}\text { Odds ratio } \\
(95 \% \mathrm{Cl})\end{array}$ & $\begin{array}{l}P \\
\text { value }\end{array}$ & $\begin{array}{l}\text { Odds ratio } \\
(95 \% \mathrm{Cl})\end{array}$ & $\begin{array}{l}P \\
\text { value }\end{array}$ & $\begin{array}{l}\text { Odds ratio } \\
(95 \% \mathrm{Cl})\end{array}$ & $\begin{array}{l}P \\
\text { value }\end{array}$ & $\begin{array}{l}\text { Odds ratio } \\
(95 \% \mathrm{Cl})\end{array}$ & $\begin{array}{l}P \\
\text { value }\end{array}$ \\
\hline$\leq$ US\$35, 000 & 0.61 (0.40 to 0.94$)$ & 0.02 & 0.78 (0.60 to 1.02$)$ & 0.07 & 0.77 (0.50 to 1.19) & 0.24 & 0.91 (0.68 to 1.25$)$ & 0.56 \\
\hline $\begin{array}{l}>\text { US\$35, } 000 \text { to US\$45, } \\
000\end{array}$ & 0.68 (0.49 to 0.94$)$ & 0.02 & 0.96 (0.78 to 1.20$)$ & 0.75 & 0.90 (0.60 to 1.34$)$ & 0.60 & 1.09 (0.83 to 1.44$)$ & 0.52 \\
\hline > US\$45, 000 (ref) & 1.00 & & 1.00 & & 1.00 & & 1.00 & \\
\hline
\end{tabular}

Data were additionally adjusted for the following variables at baseline: age category, gender, body mass index (BMI) category, Deyo-Charlson index, American Society of Anesthesiologists (ASA) class, distance, operative diagnosis, implant fixation, preoperative pain (for pain models) and preoperative functional limitation (for functional limitation models). Significant variables in each model included the following: (1) 2-year pain model: age $(P=0.03)$ and preoperative pain $(P=0.003)$; $(2) 2$-year activity limitation model: age $(P<0.001)$, gender $(P<0.001)$, body mass index $(P<0.001)$, ASA class $(P<0.001)$ and preoperative activity limitation $(P<0.001)$; $(3) 5$-year pain model: ASA class $(P<0.001)$, distance from medical center $(P=0.02)$ and implant fixation $(P=0.01)$; $(4)$ 5-year activity limitation model: age $(P<0.001)$, gender $(P<0.001)$, body mass index $(P<0.001)$, ASA class $(P<0.001)$, Deyo-Charlson index $(P=0.02)$ and preoperative activity limitation $(P<0.001)$. 
Table 5 Multivariable-adjusted association of income with improvement in knee function after primary TKA

\begin{tabular}{|c|c|c|c|c|c|c|c|c|}
\hline & \multicolumn{4}{|l|}{2 years } & \multicolumn{4}{|l|}{5 years } \\
\hline & \multicolumn{2}{|l|}{ Better } & \multicolumn{2}{|l|}{ Much better } & \multicolumn{2}{|l|}{ Better } & \multicolumn{2}{|l|}{ Much better } \\
\hline & $\begin{array}{l}\text { Odds ratio } \\
(95 \% \mathrm{Cl})\end{array}$ & $\begin{array}{l}P \\
\text { value }\end{array}$ & $\begin{array}{l}\text { Odds ratio } \\
(95 \% \mathrm{Cl})\end{array}$ & $\begin{array}{l}P \\
\text { value }\end{array}$ & $\begin{array}{l}\text { Odds ratio } \\
(95 \% \mathrm{Cl})\end{array}$ & $\begin{array}{l}P \\
\text { value }\end{array}$ & $\begin{array}{l}\text { Odds ratio } \\
(95 \% \mathrm{Cl})\end{array}$ & $\begin{array}{l}P \\
\text { value }\end{array}$ \\
\hline$\leq$ US\$35, 000 & 1.9 (1.0 to 3.6$)$ & 0.06 & $1.4(0.8$ to 2.5$)$ & 0.26 & 1.7 (0.8 to 3.4$)$ & 0.16 & 1.5 (0.9 to 2.8$)$ & 0.15 \\
\hline $\begin{array}{l}>\text { US\$35, } 000 \text { to US\$45, } \\
000\end{array}$ & 1.4 (0.8 to 2.4$)$ & 0.25 & 1.4 (0.9 to 2.3$)$ & 0.14 & 1.2 (0.6 to 2.2 ) & 0.64 & 1.0 (0.6 to 1.7$)$ & 0.93 \\
\hline > US\$45, 000 (ref) & 1.00 & & 1.00 & & 1.00 & & 1.00 & \\
\hline
\end{tabular}

Data additionally adjusted for the following variables at baseline: age category, gender, body mas index (BMI) category, Deyo-Charlson index, American Society of Anesthesiologists (ASA) class, distance, operative diagnosis, implant fixation, preoperative pain (for pain models) and preoperative functional limitation (for functional limitation models). Significant variables in each model included the following: (1) 2-year model: ASA class III/IV $(P<0.01)$ with lower odds for much better status and distance $>100$ to 500 miles with lower odds for much better status $(P=0.03)$; and preoperative activity limitation $(P<0.001)$; $(2)$ 5-year model: ASA class III/IV $(P<0.01)$ with lower odds for much better status.

significance was not met $(P=0.07)$, likely due to a small sample size. Thus, this earlier study did provide hypothesis generation for better pain outcomes in lower income groups, now confirmed in our study with ten times the sample size. Most literature regarding poorer health outcomes in those with lower income comes from pregnancy and other conditions. However, several important considerations make the findings from our study and the earlier international randomized study compatible, rather than contradictory, with the existing literature on income and outcomes.

First, the outcome described here is a patient-reported outcome (pain), which is likely influenced as much or more by social contextual factors as it is impacted by comorbidity load (presumed higher in lower income individuals). This is in contrast to mortality and other endorgan damage outcomes (the so called 'hard outcomes'), which may be influenced far more by comorbidity. Second, lower income [46] and poorer preoperative functional status [47] have both been shown to be associated with higher expectations of joint replacement. Higher expectations are associated with better outcomes $[48,49]$. Thus, lower income individuals would be expected to report better patient-reported outcomes after TKA than those with higher incomes. Third, studies in other diseases indicated that several social contextual factors including social support impact health outcomes, perhaps more than income [50-52]. More studies are needed to understand the association of income and other contextual factors with pain and function outcomes after TKA.

Another interesting finding from our study was that patients in the lowest income category were twice as likely than those in the highest income category to report a 'better' improvement in the index knee function 2 years after primary TKA. This finding should not be surprising at all considering that those in the lower income categories have worse preoperative functional status $[18,20,53]$, but similar postoperative function after TKA $[18,53]$, than those in the higher categories. Since those with a lower income have worse scores preoperatively, they have a much greater chance to improve their knee function, compared to those on a higher income. Our study corroborates and extends these earlier findings. The simple knee function improvement question used in this study has been used previously [32], and may be easily implemented in clinical practice in addition to longer composite pain and function instruments used in clinical research. The knee function improvement used in this study is clinically meaningful at patient level, and much easier to interpret as compared to a change in mean function score, usually presented for an entire cohort (some patients improving dramatically, others not at all). In addition, activity limitations were lesser in lower income categories compared to the highest income category, although they did not reach statistical significance.

\section{Conclusions}

In summary, patients in lower income groups had better pain outcomes and more improvement in index knee function at 2 years after primary TKA. Similar differences by income were noted at 5 years, although they were not significant. These data are reassuring in that, at least for primary TKA, lower income is not a risk factor for poor outcomes; on the contrary it may be associated with better outcomes. Future studies should investigate the reasons for better outcomes after TKA in patients with lower incomes.

\section{Additional material}

Additional file 1: Sensitivity analyses additionally adjusting multivariable analyses for preoperative activity limitation in pain outcome models and preoperative pain in activity limitation models. This table shows the sensitivity analyses that adjusted the main models for pain and activity limitation additionally for preoperative pain and activity limitation, respectively.

Additional file 2: Sensitivity analyses using a different income category cut-off of US\$39, 000 for the lowest category in multivariable-adjusted analyses. This table shows the sensitivity analyses that used a different cut-off for income for the lowest income category of US\$39, 000 instead of US\$35, 000 (as in the main model). 
Additional file 3: Sensitivity analyses using body mass index (BMI) and age as continuous variables in multivariable-adjusted analyses. this table shows the sensitivity analyses that adjusted the main model for a continuous age and BMI variable instead of the categorical variable for both.

\section{Abbreviations}

ASA: American Society of Anesthesiologists; BMI: body mass index; GEE: generalized estimating equations; PROs: patient-reported outcomes; TKA: total knee arthroplasty.

\section{Authors' contributions}

JAS developed the study concept and protocol, obtained IRB approval, designed and reviewed statistical analyses, drafted and revised the manuscript and submitted the manuscript. DGL reviewed the study concept and protocol, and participated in its design and coordination, reviewed analyses and reviewed and revised the manuscript. Both authors read and approved the final manuscript.

\section{Competing interests}

The authors report no financial conflicts related directly to this study. JAS has received research grants from Takeda and Savient; and consultant fees from URL pharmaceuticals, Savient, Takeda, Regeneron, Allergan, Ardea and Novartis. DGL has received royalties/speaker fees from Zimmer, Orthosonic and Osteotech, has been a paid consultant to and owns stock in Pipeline Biomedical and has received institutional research funds from DePuy, Stryker, Biomet and Zimmer.

The views expressed in this article are those of the authors and do not necessarily reflect the position or policy of the Department of Veterans Affairs or the United States government.

\section{Acknowledgements}

This material is the result of work supported by Mayo Clinic Orthopedic Surgery research funds and the resources and use of facilities at the Birmingham VA Medical Center, Alabama, USA. JAS is also supported by grants from the Agency for Health Quality and Research Center for Education and Research on Therapeutics (CERTs), National Institute of Arthritis, Musculoskeletal and Skin Diseases (NIAMS), National Institute of Aging (NIA) and National Cancer Institute (NCI).

\section{Author details}

${ }^{1}$ Medicine Service and Center for Surgical Medical Acute are Research and Transitions (C-SMART), Birmingham VA Medical Center, 700 19th Street South Birmingham, AL 35233, USA. ${ }^{2}$ Department of Medicine at School of Medicine, and Division of Epidemiology at School of Public Health, University of Alabama, 20th Street South, FOT 805B, Birmingham, AL 35294, USA. ${ }^{3}$ Department of Orthopedic Surgery, Mayo Clinic College of Medicine, 2001 st St SW, Rochester, MN 55905, USA.

\section{Received: 30 August 2012 Accepted: 6 March 2013}

Published: 6 March 2013

\section{References}

1. Singh JA, Vessely MB, Harmsen WS, Schleck CD, Melton $L$, Kurland RL, Berry DJ: A population-based study of trends in the use of total hip and total knee arthroplasty, 1969-2008. Mayo Clin Proc 2010, 85:898-904.

2. Ethgen O, Bruyere O, Richy F, Dardennes C, Reginster JY: Health-related quality of life in total hip and total knee arthroplasty. A qualitative and systematic review of the literature. J Bone Joint Surg Am 2004, 86-A:963-974.

3. Brander V, Gondek S, Martin E, Stulberg SD: Pain and depression influence outcome 5 years after knee replacement surgery. Clin Orthop Relat Res 2007, 464:21-26.

4. Forsythe ME, Dunbar MJ, Hennigar AW, Sullivan MJ, Gross M: Prospective relation between catastrophizing and residual pain following knee arthroplasty: two-year follow-up. Pain Res Manag 2008, 13:335-341.

5. Singh JA, Gabriel S, Lewallen D: The impact of gender, age, and preoperative pain severity on pain after TKA. Clin Orthop Relat Res 2008, 466:2717-2723.
6. Singh JA, Lewallen D: Age, gender, obesity, and depression are associated with patient-related pain and function outcome after revision total hip arthroplasty. Clin Rheumatol 2009, 28:1419-1430.

7. Singh JA, Lewallen DG: Predictors of activity limitation and dependence on walking aids after primary total hip arthroplasty. J Am Geriatr SoC 2010, 58:2387-2393.

8. Singh JA, O'Byrne M, Harmsen S, Lewallen D: Predictors of moderatesevere functional limitation after primary total knee arthroplasty (TKA): 4701 TKAs at 2-years and 2935 TKAs at 5-years. Osteoarthritis Cartilage 2010, 18:515-521.

9. Singh JA, Gabriel SE, Lewallen DG: Higher body mass index is not associated with worse pain outcomes after primary or revision total knee arthroplasty. J Arthroplasty 2011, 26:366-374 e361.

10. Hawkins K, Escoto KH, Ozminkowski RJ, Bhattarai GR, Migliori RJ, Yeh CS: Disparities in major joint replacement surgery among adults with Medicare supplement insurance. Popul Health Manag 2011, 14:231-238.

11. Bederman SS, Rosen CD, Bhatia NN, Kiester PD, Gupta R: Drivers of surgery for the degenerative hip, knee, and spine: a systematic review. Clin Orthop Relat Res 2012, 470:1090-1105.

12. Bang H, Chiu YL, Memtsoudis SG, Mandl LA, Della Valle AG, Mushlin Al, Marx RG, Mazumdar M: Total hip and total knee arthroplasties: trends and disparities revisited. Am J Orthop (Belle Mead NJ) 2010, 39:E95-102.

13. Dunlop DD, Song J, Manheim LM, Chang RW: Racial disparities in joint replacement use among older adults. Med Care 2003, 41:288-298.

14. Agabiti N, Picciotto S, Cesaroni G, Bisanti L, Forastiere F, Onorati R, Pacelli B, Pandolfi P, Russo A, Spadea T, Perucci CA: The influence of socioeconomic status on utilization and outcomes of elective total hip replacement: a multicity population-based longitudinal study. Int I Qual Health Care 2007, 19:37-44.

15. Irgit $\mathrm{K}$, Nelson $\mathrm{CL}$ : Defining racial and ethnic disparities in THA and TKA. Clin Orthop Relat Res 2011, 469:1817-1823.

16. Escalante A, Espinosa-Morales R, del Rincon I, Arroyo RA, Older SA: Recipients of hip replacement for arthritis are less likely to be Hispanic, independent of access to health care and socioeconomic status. Arthritis Rheum 2000, 43:390-399.

17. Hawker GA, Wright JG, Glazier RH, Coyte PC, Harvey B, Williams ال I, Badley EM: The effect of education and income on need and willingness to undergo total joint arthroplasty. Arthritis Rheum 2002, 46:3331-3339.

18. Davis ET, Lingard EA, Schemitsch EH, Waddell JP: Effects of socioeconomic status on patients' outcome after total knee arthroplasty. Int J Qual Health Care 2008, 20:40-46.

19. Mahomed NN, Barrett JA, Katz JN, Phillips CB, Losina E, Lew RA, Guadagnoli E, Harris WH, Poss R, Baron JA: Rates and outcomes of primary and revision total hip replacement in the United States medicare population. J Bone Joint Surg Am 2003, 85-A:27-32.

20. Allen Butler R, Rosenzweig S, Myers L, Barrack RL: The Frank Stinchfield Award: the impact of socioeconomic factors on outcome after THA: a prospective, randomized study. Clin Orthop Relat Res 2011, 469:339-347.

21. Berry DJ, Kessler M, Morrey BF: Maintaining a hip registry for 25 years. Mayo Clinic experience. Clin Orthop Relat Res 1997, Nov:61-68.

22. Rand JA, IIstrup DM: Survivorship analysis of total knee arthroplasty. Cumulative rates of survival of 9200 total knee arthroplasties. J Bone Joint Surg Am 1991, 73:397-409.

23. Rand JA, Trousdale RT, Ilstrup DM, Harmsen WS: Factors affecting the durability of primary total knee prostheses. J Bone Joint Surg Am 2003, 85-A:259-265.

24. McGrory BJ, Morrey BF, Rand JA, Ilstrup DM: Correlation of patient questionnaire responses and physician history in grading clinical outcome following hip and knee arthroplasty. A prospective study of 201 joint arthroplasties. J Arthroplasty 1996, 11:47-57.

25. Lingard EA, Katz JN, Wright RJ, Wright EA, Sledge CB: Validity and responsiveness of the Knee Society Clinical Rating System in comparison with the SF-36 and WOMAC. J Bone Joint Surg Am 2001, 83-A:1856-1864.

26. Liow RY, Walker K, Wajid MA, Bedi G, Lennox CM: Functional rating for knee arthroplasty: comparison of three scoring systems. Orthopedics 2003, 26:143-149.

27. Kreibich DN, Vaz M, Bourne RB, Rorabeck CH, Kim P, Hardie R, Kramer J, Kirkley $A$ : What is the best way of assessing outcome after total knee replacement? Clinical Orthop Relat Res 1996, Oct:221-225. 
28. Insall JN, Dorr LD, Scott RD, Scott WN: Rationale of the Knee Society clinical rating system. Clin Orthop Relat Res 1989, Nov:13-14.

29. Singh JA, O'Byrne MM, Harmsen WS, Lewallen DG: Predictors of moderatesevere functional limitation 2 and 5 years after revision total knee arthroplasty. J Arthroplasty 2010, 25:1091-1095.

30. Singh JA, Lewallen D: Predictors of pain and use of pain medications following primary total hip arthroplasty (THA): 5, 707 THAs at 2-years and 3, 289 THAs at 5-years. BMC Musculoskelet Disord 2010, 11:90.

31. US Department of Health \& Human Services: Prior HHS Poverty Guidelines and Federal Register References [http://aspe.hhs.gov/poverty/figures-fed-reg. shtml].

32. Singh JA, O'Byrne MM, Colligan RC, Lewallen DG: Pessimistic explanatory style: a psychological risk factor for poor pain and functional outcomes two years after knee replacement. J Bone Joint Surg Br 2010, 92:799-806.

33. Jones CA, Voaklander DC, Suarez-Alma ME: Determinants of function after total knee arthroplasty. Phys Ther 2003, 83:696-706.

34. Schneider M, Kawahara I, Ballantyne G, McAuley C, Macgregor K, Garvie R, McKenzie A, Macdonald D, Breusch SJ: Predictive factors influencing fast track rehabilitation following primary total hip and knee arthroplasty. Arch Orthop Trauma Surg 2009, 129:1585-1591.

35. Gordon SM, Culver DH, Simmons BP, Jarvis WR: Risk factors for wound infections after total knee arthroplasty. Am J Epidemiol 1990, 131:905-916.

36. Bourne R, Mukhi S, Zhu N, Keresteci M, Marin M: Role of obesity on the risk for total hip or knee arthroplasty. Clin Orthop Relat Res 2007, 465:185-188.

37. World Health Organization: Obesity: preventing and managing the global epidemic Geneva, Switzerland: World Health Organization; 2000.

38. Deyo RA, Cherkin DC, Ciol MA: Adapting a clinical comorbidity index for use with ICD-9-CM administrative databases. J Clin Epidemiol 1992, 45:613-619.

39. Charlson ME, Pompei P, Ales KL, Mackenzie CR: A new method of classifying prognostic comorbidity in longitudinal studies: development and validation. J Chronic Dis 1987, 40:373-383.

40. Charlson ME, Sax FL, Mackenzie CR, Braham RL, Fields SD, Douglas RG Jr: Morbidity during hospitalization: can we predict it? J Chronic Dis 1987, 40:705-712.

41. Dripps RD, Lamont A, Eckenhoff JE: The role of anesthesia in surgical mortality. JAMA 1961, 178:261-266.

42. Weaver F, Hynes D, Hopkinson W, Wixson R, Khuri S, Daley J, Henderson WG: Preoperative risks and outcomes of hip and knee arthroplasty in the Veterans Health Administration. J Arthroplasty 2003, 18:693-708.

43. Biesheuvel CJ, Vergouwe Y, Steyerberg EW, Grobbee DE, Moons KG: Polytomous logistic regression analysis could be applied more often in diagnostic research. J Clin Epidemiol 2008, 61:125-134.

44. Houston TK, Scarinci IC, Person SD, Greene PG: Patient smoking cessation advice by health care providers: the role of ethnicity, socioeconomic status, and health. Am J Public Health 2005, 95:1056-1061.

45. Asch DA, Jedrziewski MK, Christakis NA: Response rates to mail surveys published in medical journals. J Clin Epidemiol 1997, 50:1129-1136.

46. Jourdan C, Poiraudeau S, Descamps S, Nizard R, Hamadouche M, Anract P, Boisgard S, Galvin M, Ravaud P: Comparison of patient and surgeon expectations of total hip arthroplasty. PLoS One 2012, 7:e30195.

47. Mancuso CA, Sculco TP, Salvati EA: Patients with poor preoperative functional status have high expectations of total hip arthroplasty. $J$ Arthroplasty 2003, 18:872-878.

48. Kalauokalani D, Cherkin DC, Sherman KJ, Koepsell TD, Deyo RA: Lessons from a trial of acupuncture and massage for low back pain: patient expectations and treatment effects. Spine (Phila Pa 1976) 2001, 26:1418-1424.

49. Mahomed NN, Liang MH, Cook EF, Daltroy LH, Fortin PR, Fossel AH, Katz JN: The importance of patient expectations in predicting functional outcomes after total joint arthroplasty. J Rheumatol 2002, 29:1273-1279.

50. Achhra AC, Phanuphak P, Amin J: Long-term immunological outcomes in treated HIV-infected individuals in high-income and low-middle income countries. Curr Opin HIV AIDS 2011, 6:258-265.

51. Ford N, Kirby C, Singh K, Mills EJ, Cooke G, Kamarulzaman A, Ducros P: Chronic hepatitis $C$ treatment outcomes in low- and middle-income countries: a systematic review and meta-analysis. Bull World Health Organ 2012, 90:540-550.
52. Wen M, Browning CR, Cagney KA: Poverty, affluence, and income inequality: neighborhood economic structure and its implications for health. Soc Sci Med 2003, 57:843-860

53. Jenkins PJ, Perry PR, Yew Ng C, Ballantyne JA: Deprivation influences the functional outcome from total hip arthroplasty. Surgeon 2009, 7:351-356

\section{Pre-publication history}

The pre-publication history for this paper can be accessed here: http://www.biomedcentral.com/1741-7015/11/62/prepub

doi:10.1186/1741-7015-11-62

Cite this article as: Singh and Lewallen: Income and patient-reported outcomes (PROs) after primary total knee arthroplasty. BMC Medicine $201311: 62$

\section{Submit your next manuscript to BioMed Central and take full advantage of:}

- Convenient online submission

- Thorough peer review

- No space constraints or color figure charges

- Immediate publication on acceptance

- Inclusion in PubMed, CAS, Scopus and Google Scholar

- Research which is freely available for redistribution

Submit your manuscript at www.biomedcentral.com/submit
Ciomed Central 